\title{
Photovoltaic Actuated Induction Motor for Driving Electric Vehicle
}

\author{
Vinay Anand
}

\begin{abstract}
The paper depicts about the photovoltaic actuated induction motor for driving electric vehicle, helps in improving the efficiency of electric vehicles, the advance "power electronic interface" is used. System efficiency and reliability are improved by this proposed idea, and current or voltage ripple can be effectively reduced. Using this proposed model reduces the component's dimensions (active and passive), thus reducing costs and this technology reducing stress on switching devices. The designing and analysis of proposed model is done by using MATLAB / Simulink.
\end{abstract}

Keywords- Photovoltaic, induction motor, electric vehicle, electronic interface.

\section{INTRODUCTION}

Automakers are turning to pollution-free electrical running vehicle technology due to drastic change in the climate. With several advancement in battery/cell technologies with "power electronics interface" (PEI) and control strategy, these battery running by electric vehicles (BEV) can replace IC engines. BEV is called a zeroemission vehicle because energy consumption is unstable and local emissions are zero, which thereby reduce the dependence on energy[1], [2]. However, there exists limitations in $\mathrm{BEV}$ which includes cruising range, charging time, battery replacement throughout life, reliance in power electronics equipment, and ultimately high initial cost.

The main components used in EV vehicle systems are motors, power supplies, controllers, chargers, and drivetrains. So far, most EV systems are developed using DC. However, due to shortcomings of DC machines, EV developers have different types of AC Machine. Induction motors require less maintenance and are less expensive and simple. Therefore, it attracts EV system developers[3]-[5]. Figure 1 illustrates the Schematic of battery vehicle and figure 2 represents the controlling scheme of BEV.

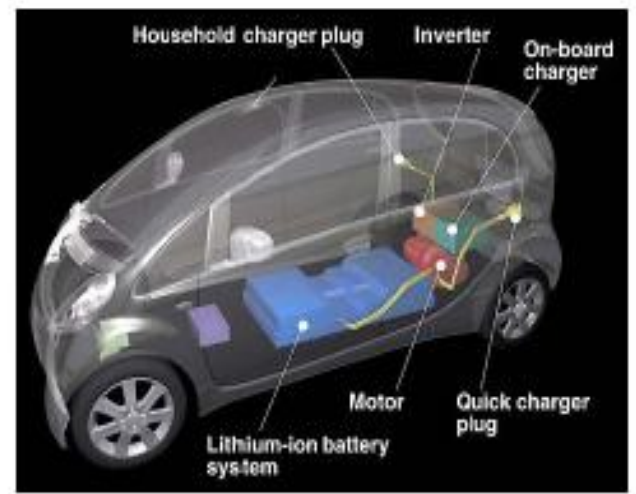

Fig.1 Electric Vehicle

Revised Manuscript Received on 14 August, 2019.

Vinay Anand,Department of Electrical Engineering, Sanskriti University, UttarPradesh, India.(Email: sanpubip@gmail.com)

\section{DESIGNING OF BEV}

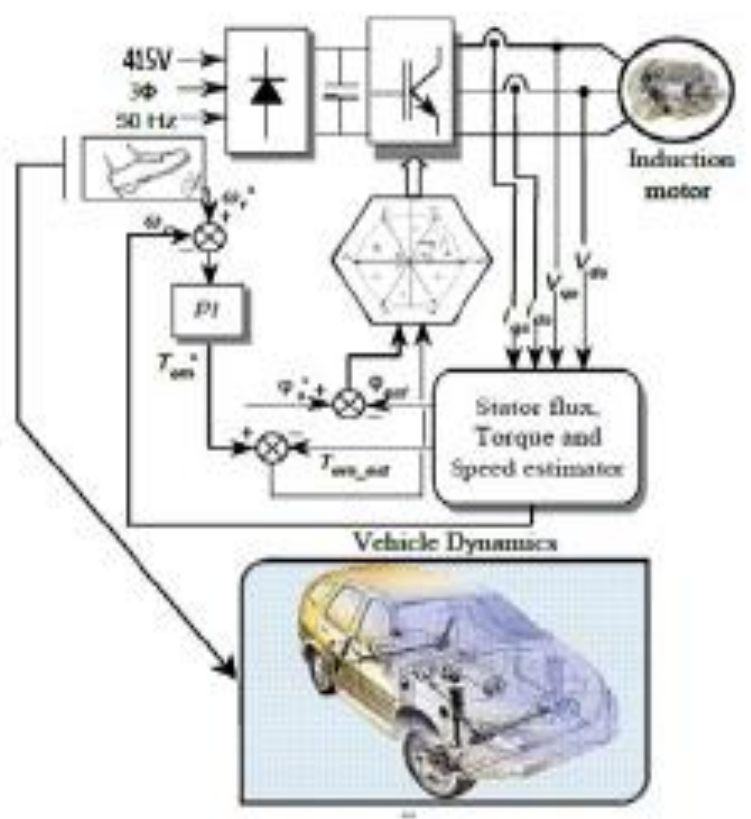

Fig.2 Controlling Scheme of BEV

\section{A. DC-DC Boost Converter}

Boost Converters operates in charge or discharge mode relies on switching and controls the switching action of the switch. The boost circuit contains inductor, a high-frequency switch MOSFET, a diode, and a filter across the load. converter boosts the voltage and provides it to controller.

The relationship between load voltage and power supply voltage is given as-

$$
\begin{aligned}
V_{0} & =\frac{V_{3}}{(1-D)} \\
D & =\frac{t_{\text {a }}}{T}
\end{aligned}
$$

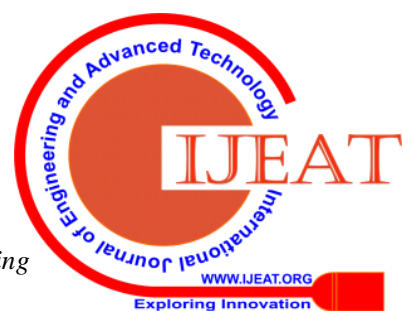




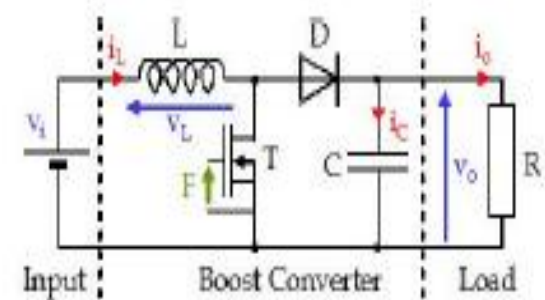

a) Boost converter circuit

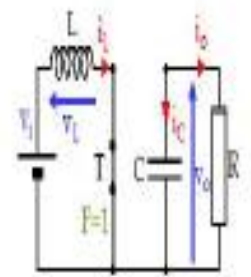

Ittan D t thenth

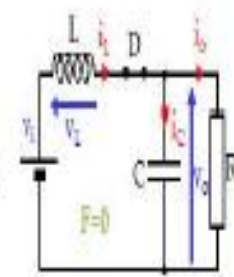

[saleoft, D satern

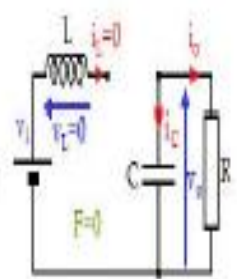

Itste off.Dstationt

\section{b) Operating phases}

Fig.2 circuit diagram along operating phases of boost converter

\section{B. Controlled Scheme of Induction Motor}

In the paper, control technology of IM is proposed. The most popularadvancement is based on vector control technology used by automotive applications. In this case, the Controlled torque has been extended to transients, allowing better dynamic performance. In this paper of EV applications, proposal of DTC application has been done due to its simplicity [6]. No speed or position encoding is involved in DTC and only measures current to estimate flux and torque. Reference speed is taken as input to the DC motor. This reference speed is applied directly to the vehicle pedal. In this model the PIC controller operates in closed loop structure to regulate motor speed and reduce "steady state error". The error signal is being generated in closed loop system by analysing the actual speed of motor. At the reference speed,due to the variance in the actual speed and the targeted speed, the amplitude and polarity of Error signal gets changed.

\section{Modeling Electric Motor}

IM is the best choice for EV systems in the automobile industry due to its robustness, reliability and cheap cost. Induction motor stator current is separated into magnetic fluxes and torque using field-oriented control (FOC), providing independent commands for motor torque to operate accurately. This control is a "separately excited DC motor" [7]-[9]. The main purpose of IFOC is to separate completely the direct and quadrature currents. In other words, a slight variation in torque changes the orthogonal current, and slight change in DC current affects magnitude of the flux linkage. This requires the IM dq proposed model in the reference frame that is synchronous in nature to implement the FOC concept.

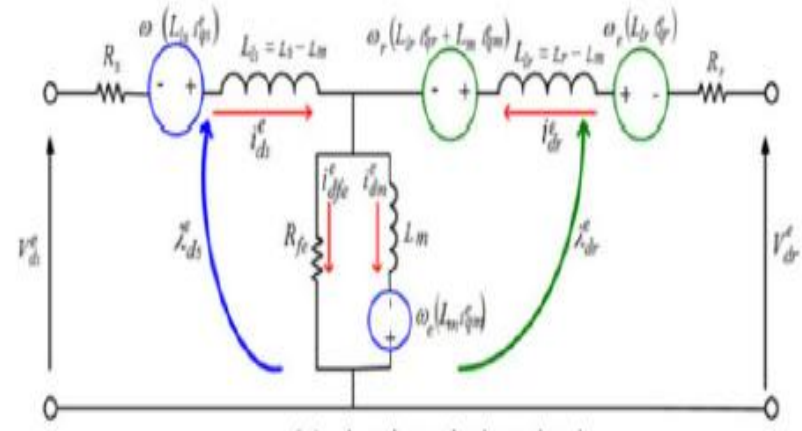

(a) d-axis equivalent circuit

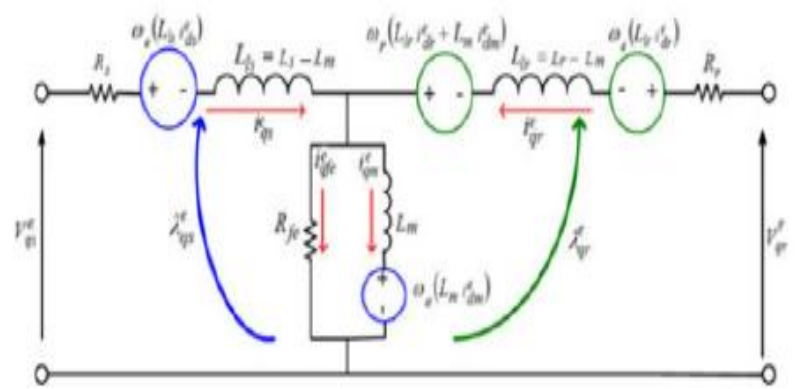

Fig.3 Dq equivalent model of induction motor with synchronous reference frame.

This paper uses a 3-phase IM dq model with a synchronous reference frame for dynamic analysis. As depicted in Figure 3, the dq model considers the core loss and referred as the core resistance $\mathrm{Rf}$ [5]-[8]

The rotor and stator voltage equation for the synchronous frame of reference is written as-

$$
\begin{aligned}
& v_{q s}^{e}=R_{s} i_{q s}^{e}+L_{s s} \frac{d i_{q s}^{\tau}}{d t}+L_{m} \frac{d i_{q m}^{\tau}}{d t}+w_{e}\left(L_{l s} i_{d s}^{e}+L_{m} i_{d m}^{e}\right) \\
& v_{d s}^{e}=R_{s} i_{d s}^{e}+L_{l s} \frac{d i_{d s}^{e}}{d t}+L_{m} \frac{d i_{d m}^{e}}{d t}-w_{e}\left(L_{l s} i_{q s}^{e}+L_{m} i_{q m}^{e}\right) \\
& v_{q r}^{e}=0=R_{r} l_{q r}^{e}+L_{l r} \frac{d i_{q r}^{e}}{d t}+L_{m} \frac{d l_{q m}^{e}}{d t}+w_{s l}\left(L_{r r} i_{d r}^{e}+L_{m} i_{d m}^{e}\right) \\
& v_{d r}^{e}=0=R_{r} i_{d r}^{e}+L_{l r} \frac{d l_{d r}^{e}}{d t}+L_{m} \frac{d l_{d m}^{e}}{d t}-w_{s l}\left(L_{l r} i_{q r}^{e}+L_{m} i_{q m}^{e}\right)
\end{aligned}
$$

where the magnetizing currents can be given as

$i_{q m}^{e}=i_{q s}^{e}+i_{q r}^{e}-i_{q f e}^{e}$

$i_{d m}^{e}=i_{d s}^{e}+i_{d r}^{e}-i_{d f e}^{e}$

The electrical torque equation can be expressed as

$T_{e}=\frac{3}{2} \frac{p}{2} \frac{L_{m}}{L_{r}}\left[i_{q s}^{e} i_{d r}^{e}-i_{d r}^{e} i_{q r}^{e}\right]$ 
where:

$P=$ number of poles of the machine;

$V d s, V q s=d q$ axes of the stator voltages;

$i d r, i q r=$ rotor currents;

$i d m, i q m=d q$ axes magnetizing currents;

$R s, R r=$ stator and rotor resistances;

$L l s, L l r=$ self-inductance of the stator and rotor

\section{RESULT AND DISCUSSION}

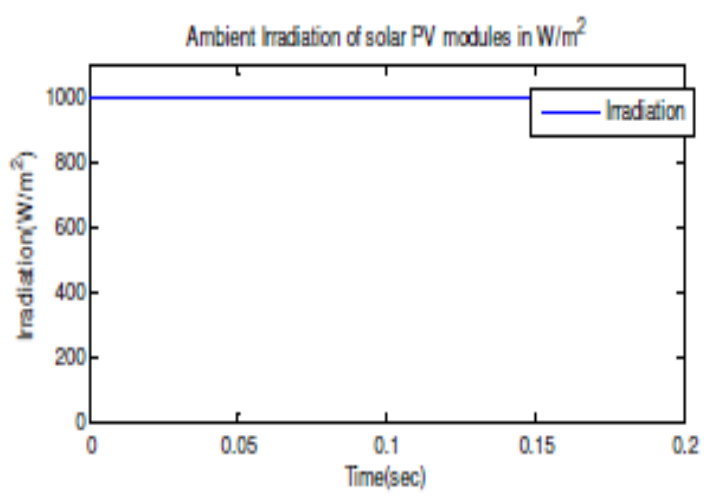

Fig.4 Continuous irradiation on PV module

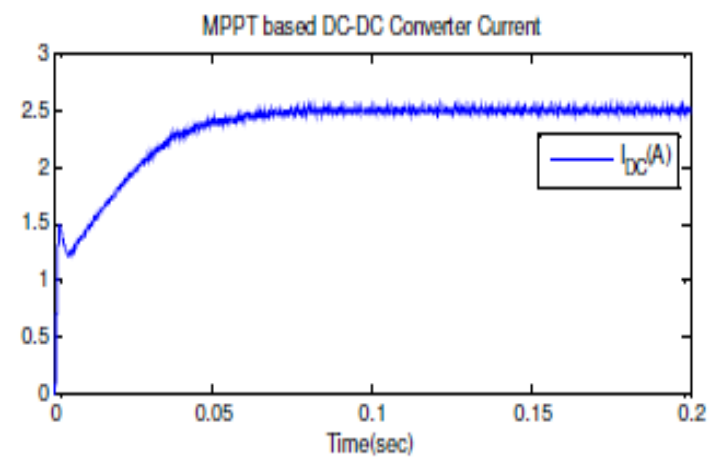

Fig.5 output of DC converter

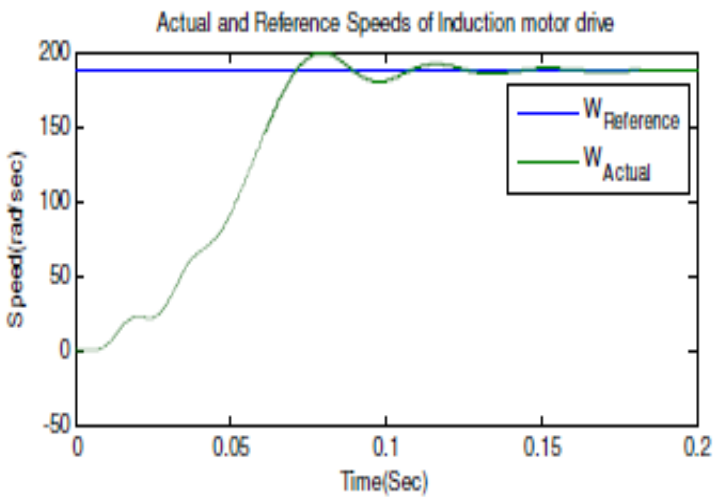

Fig.6 IM speed plot

In the proposed system, fig. 4 shows plot of the removal of solar energy incident on the module. Fig. 5 shows the output of dc converter. The MPPT based dc converter voltage is obtained after extracting the maximum value of power from MPPT and fig.6 shows the plot of speed of IM. The IM speed based on the solar irradiation incidented on the photovoltaic module. The above results are gathered after modeling of PV module, induction motor in a MATLAB software.

\section{CONCLUSION}

The complete model of PV actuated induction motor for driving electric vehicle is given is designed in a MATLAB based platform. From the above results, it is concluded that induction motor receives surplus power for driving vehicle at different loading condition. Thus, the model involves a successful practical implementation.

\section{REFERENCES}

1. W. Sierzchula, S. Bakker, K. Maat, and B. Van Wee, "The influence of financial incentives and other socioeconomic factors on electric vehicle adoption," Energy Policy, 2014.

2. J. Y. Yong, V. K. Ramachandaramurthy, K. M. Tan, and N. Mithulananthan, "A review on the state-of-the-art technologies of electric vehicle, its impacts and prospects," Renewable and Sustainable Energy Reviews. 2015.

3. A. Emadi, Y. J. Lee, and K. Rajashekara, "Power electronics and motor drives in electric, hybrid electric and plug-in hybrid electric vehicles," IEEE Transactions on Industrial Electronics. 2008.

4. J. M. Miller, "Hybrid electric vehicles," in Handbook of Automotive Power Electronics and Motor Drives, 2017.

5. J. Cao and A. Emadi, "A new battery/ultracapacitor hybrid energy storage system for electric, hybrid, and plug-in hybrid electric vehicles," IEEE Trans. Power Electron., 2012.

6. H. Liu and H. Cui, "Study on a sliding mode variable structure vector control of induction motor drives," in Proceedings of the World Congress on Intelligent Control and Automation (WCICA), 2012.

7. Y. Bekakra and D. Ben Attous, "Fuzzy sliding mode controller for doubly fed induction motor speed control," J. Fundam. Appl. Sci., vol. 2, no. 2, p. 272, 2015.

8. K. P. Ranga, G. D. Sukumar, B. Pakkiraiah, and M. S Rao, "Neuro fuzzy based indirect vector control doubly fed induction generator," in India International Conference on Power Electronics, IICPE, 2017, vol. 2016-November.

9. N. Bounar, A. Boulkroune, and F. Boudjema, "Adaptive fuzzy control of doubly-fed induction machine," Control Eng. Appl. Informatics, vol. 16, no. 2, pp. 98-110, 2014. 